\title{
A Study on Surface Wetting and Corrosion Behavior of Straightened Car Panels
}

\section{NICOLAE NAVODARIU ${ }^{1}$, IULIAN ANTONIAC ${ }^{1,2}$, ROBERT CIOCOIU ${ }^{1}$, OCTAVIAN TRANTE ${ }^{1}$, ROBERT BOLOLOI ${ }^{1}$, DIANA TABARAS ${ }^{1}$, ALEXANDRU CERNEA ${ }^{*}$, SEBASTIAN GRADINARU ${ }^{3}$}

${ }^{1}$ Politehnica University of Bucharest, Faculty of Materials Science and Engineering, 313 Splaiul Independentei Str., 060042, Bucharest, Romania

${ }^{2}$ Academy of Romanian Scientists

${ }^{3}$ University of Medicine and Pharmacy "Carol Davila" Bucharest, 37 Dionisie Lupu Str., Bucharest 030167, Romania

Abstract.Straightening of impact damaged car panels is a common practice when damaged area is small to medium. Common car panel straightening methods are hammering, heating and welding pins and pulling on the material using a device called a spot weld puller, so that the straightened metal sheet may have, as a consequence, its microstructure, stress and strain state altered. The aim of this research was to find how the above methods alter the corrosion behavior of the alloy used for car panel manufacture. Samples from similar damaged car panels were obtained, straightened, tested and compared to a sample from an original panel. Testing implied microstructure characterization, surface wetting investigation and corrosion testing. It was concluded that when straightening is carried out by hammering and using the spot weld puller the worst corrosion behavior is to be expected.

Keywords: metal straightening, car panels, wetting, microscopy, surface free energy, corrosion

\section{Introduction}

As the modern car construction is modular, post collision minor to moderate damage to car panels can be repaired by straightening the sheet metal. In Figure 1 is shown an example of direct damage that can be repaired by straightening.

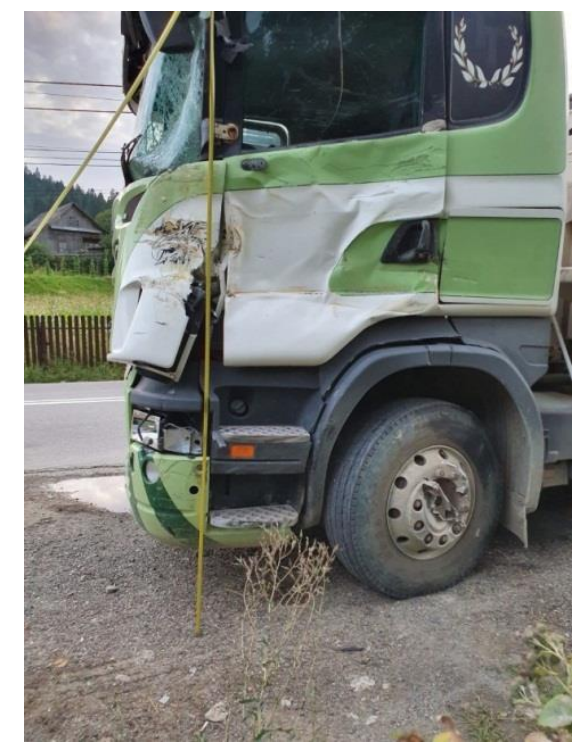

a.

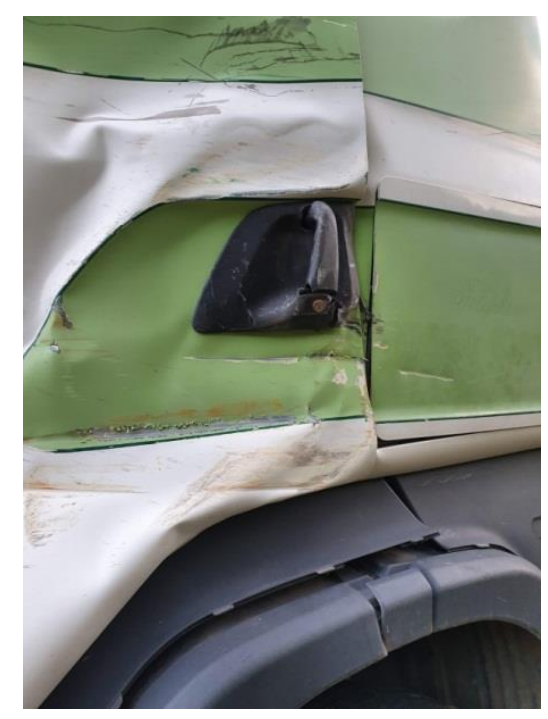

b.

Figure 1. Crash damage showing a. collision on a side and b. direct damage details

\footnotetext{
*email:alexcernea07@gmail.com
} 
In a repair shop sheet metal straightening can be performed by slight hammering (Figure 2.a), by applying heat on the highest points of the dents and creases (Figure 2.b) and forcing the metal to expand and contract and using a spot weld puller (Figure 2.c) where metal pins are welded and then the metal pulled to straighten [1].

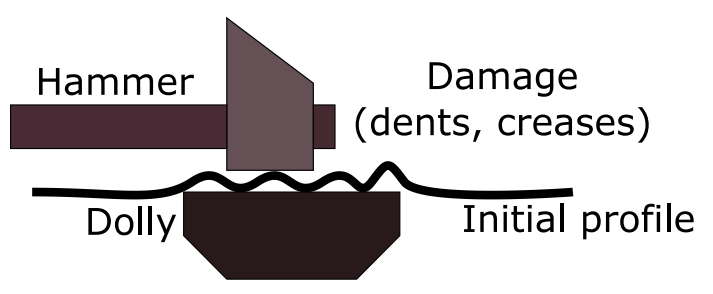

a.

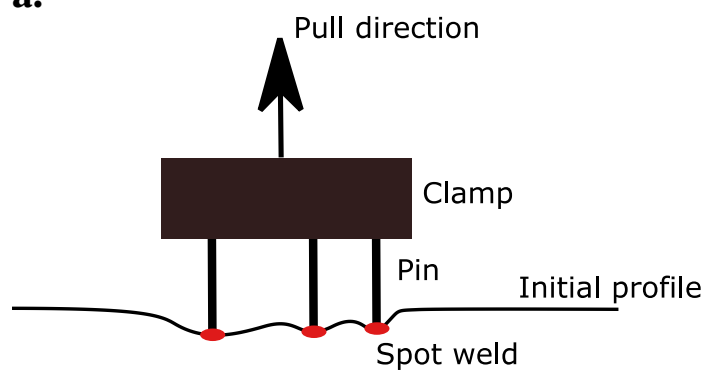

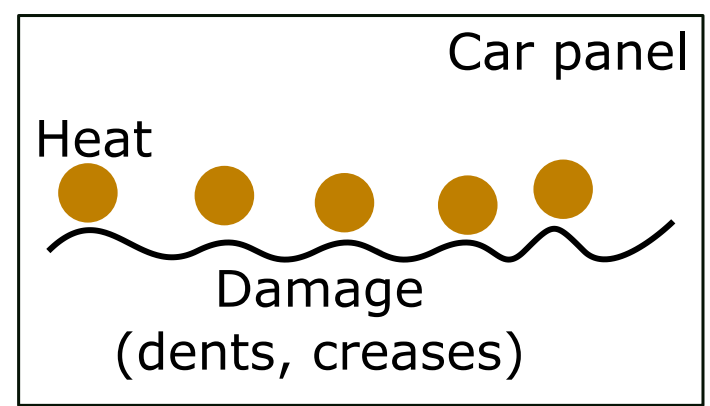

b.

Figure 2. Illustration of common straightening methods by a. hammering (cold working the sheet metal), b. heating (by flame or induction) and c. using a spot weld puller

c.

Depending upon the damage extent these procedures can be used individually or in association, such that the structure of the material is altered in that specific region and, consequently, the material properties. Given the inhomogeneous structure the material should act as a composite [2] having regions that show various physical and chemical properties.

As processing history plays an important role on the mechanical and chemical properties $[3,4,5]$, a study regarding the surface wetting properties and corrosion behavior is required for straightened panels to determine which method would comply best to in service requirements. The goal of this study was to determine the surface wetting characteristics and corrosion behavior of straightened sheet metal using repair shop procedures

\section{Materials and methods}

Four car panels, from the same car manufacturer and type, damaged in side collisions with a similar degree of direct damage were straightened in the repair shop using four methods: using a hammer and a dolly (a process similar to cold working), by heating using two heating sources: a flame (created using an oxyacetylene torch) and by induction and using a spot weld puller (a process similar to cold working, but in localized small regions weld spots are created for pin connection). A fifth as delivered panel was obtained from the car manufacturer to be used as reference in this study.

In Table 1 sample coding with the corresponding repair procedure is presented.

Table 1. Sample coding

\begin{tabular}{|c|c|}
\hline Sample code & Processing \\
\hline $\mathrm{R}$ & Reference, original panel \\
\hline $\mathrm{CW}$ & Straightened by hammering at room temperature \\
\hline $\mathrm{FH}$ & Straightened by flame heating \\
\hline $\mathrm{IH}$ & Straightened by induction heating \\
\hline $\mathrm{S}$ & Straightened using a spotter \\
\hline
\end{tabular}


Post straightening samples from the repaired areas of the car panels were obtained and used in the experimental program for chemical composition, microstructure characterization, surface wetting study and corrosion tests. The chemical composition was determined on a SPECTRO MAXx SDAROES spectrometer, scanning electron microscopy studies for microstructure characterization were performed on a Philips XL 30 ESEM TMP and contact angle measurements were performed on a Kruess Drop Shape Analyzer DSA100. Corrosion tests were performed using a potentiostat/galvanostat PARSTAT 4000 according to ASTM G5-94(2011), the Tafel curves recorded at a scan rate of $1 \mathrm{mV} / \mathrm{s}$ in a $3.5 \% \mathrm{NaCl}$ solution at $25^{\circ} \mathrm{C}$. Corrosion features were studied using an Olympus SZX7 stereomicroscope.

\section{Results and discussions}

\subsection{Chemical composition of the alloy}

The chemical composition of the alloys used for car panel manufacture was determined by optical emission spectroscopy using samples obtained from each panel used in the study from an undamaged region. On each specimen five measurements were performed and the averaged. It was observed that same alloy was used for all panels, thus in Table 2 an average chemical composition is presented.

Table 2 Chemical composition of the alloy (wt $\%)$

\begin{tabular}{|c|c|c|c|c|c|c|c|}
\hline$\% \mathrm{C}$ & $\% \mathrm{Si}$ & $\% \mathrm{Mn}$ & $\% \mathrm{P}$ & $\% \mathrm{~S}$ & $\% \mathrm{Cr}$ & $\% \mathrm{Ni}$ & $\% \mathrm{Fe}$ \\
\hline 0.0056 & 0.125 & 0.386 & 0.018 & 0.0075 & 0.037 & 0.032 & Bal. \\
\hline
\end{tabular}

According to its chemical composition the alloy is a steel namely E185, according to ISO 630 (1995).

\subsection{Alloy microstructure}

The samples used for alloy microstructure studies were obtained from damaged and straightened regions from the car panel on a longitudinal direction. The metallographic sample preparation procedure employed was one typical for steels and the etchant used was Nital $2 \%$.

The microstructure of the specimens is shown in Figure 3.

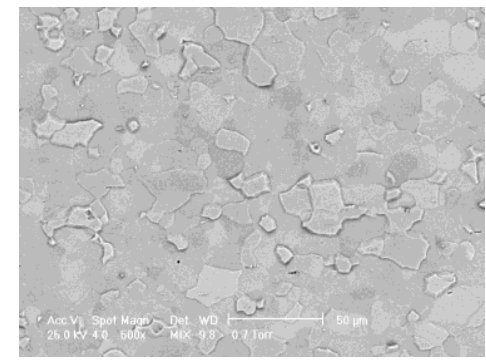

a.

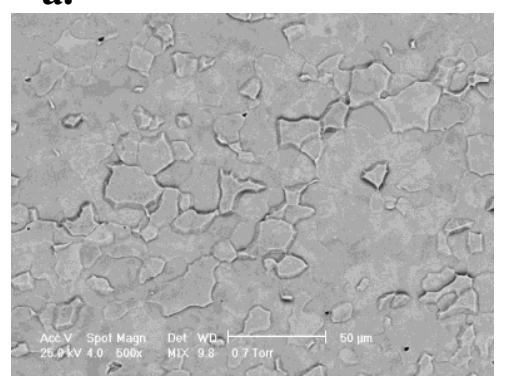

d.

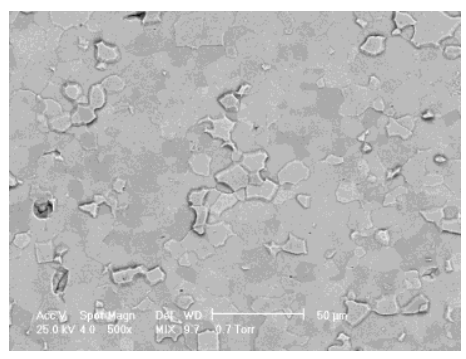

b.

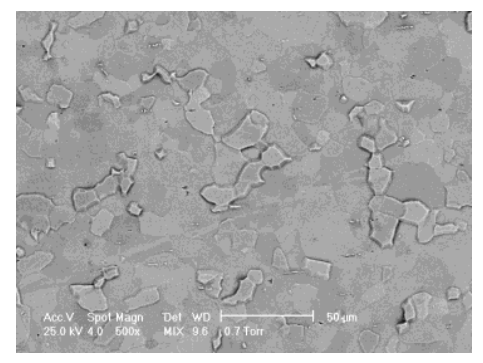

c.

Figure 3. Scanning electron micrographs showing the microstructure of sample a. R, b. CW, c. FH, d. IH and e. S at 500X magnification, Nital etch 
The microstructure of all specimens consists of ferrite and tertiary cementite on the ferritic grain boundaries. The grain size of the samples processed without heating (Figure 3.a, b and e) is uniform, while heated specimens (Figure 3.c and d.) show a slight increase in grain size. When induction heating was used the grain size increase was higher than that of the samples heated by flame. It can be stated that in induction heated specimens higher heating temperatures were reached.

The grain size is within acceptable values given that the heating process was controlled by applying a procedure created as a consequence of a previous study [6-8].

\subsection{Surface wetting}

Surface wetting was studied on rectangular specimens $20 \mathrm{~mm}$ wide $\mathrm{x} 100 \mathrm{~mm}$ long and $0.75 \mathrm{~mm}$ thick obtained from the car panels on the back side of the repair since it will be exposed to the elements. From the straightened ones the samples were cut so that original (un-deformed) and straightened regions were present in the sample. Sample cleaning was mandatory (heated samples showed scales and oxides on the surface) and performed by light grinding. All samples were cleaned this way to obtain a similar surface. Using the Kruess Drop Shape Analyzer DSA100 water drops of constant volume were placed in an array evenly spaced on the entire surface of the sample, as depicted in Figure 4.

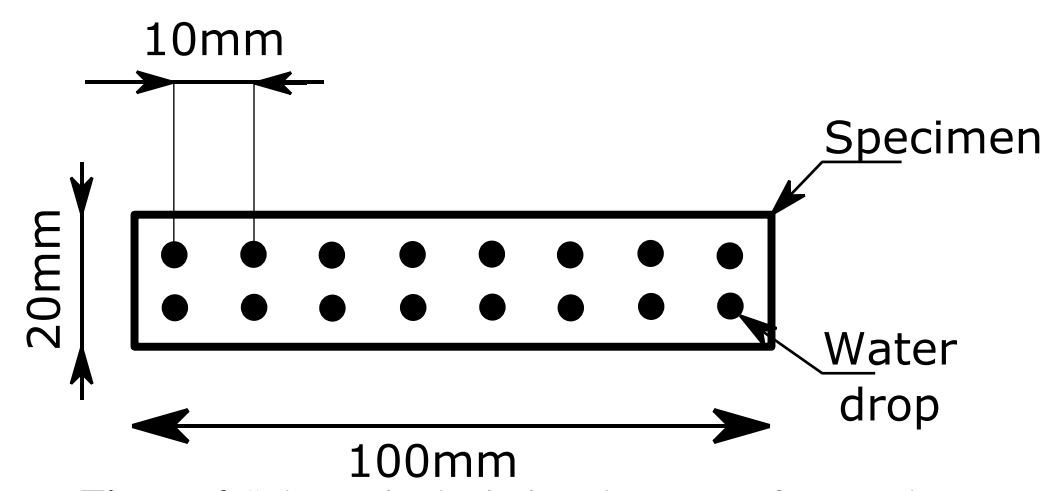

Figure 4.Schematic depicting the array of water drops deposited on the sample surface

This procedure was applied in order to observe drop shape and contact angle variation depending on the area (original or straightened). In Figure 5 a selection showing the aspect of the water drop on three areas of the material is presented - the images were chosen to illustrate the contact angle variety.

\begin{tabular}{|l|l|l|l|}
\hline Sample & Area 1 & Area 2 \\
\hline $\mathrm{R}$ & & & \\
\hline $\mathrm{CW}$ & & & \\
\hline $\mathrm{FH}$ & & \\
\hline $\mathrm{IH}$ & & \\
\hline $\mathrm{S}$
\end{tabular}


Once the areas were clearly delimited (as original or changed) five measurements were performed in each and then averaged. In Figure 6 the contact angle for water (CA-W) variation is presented.

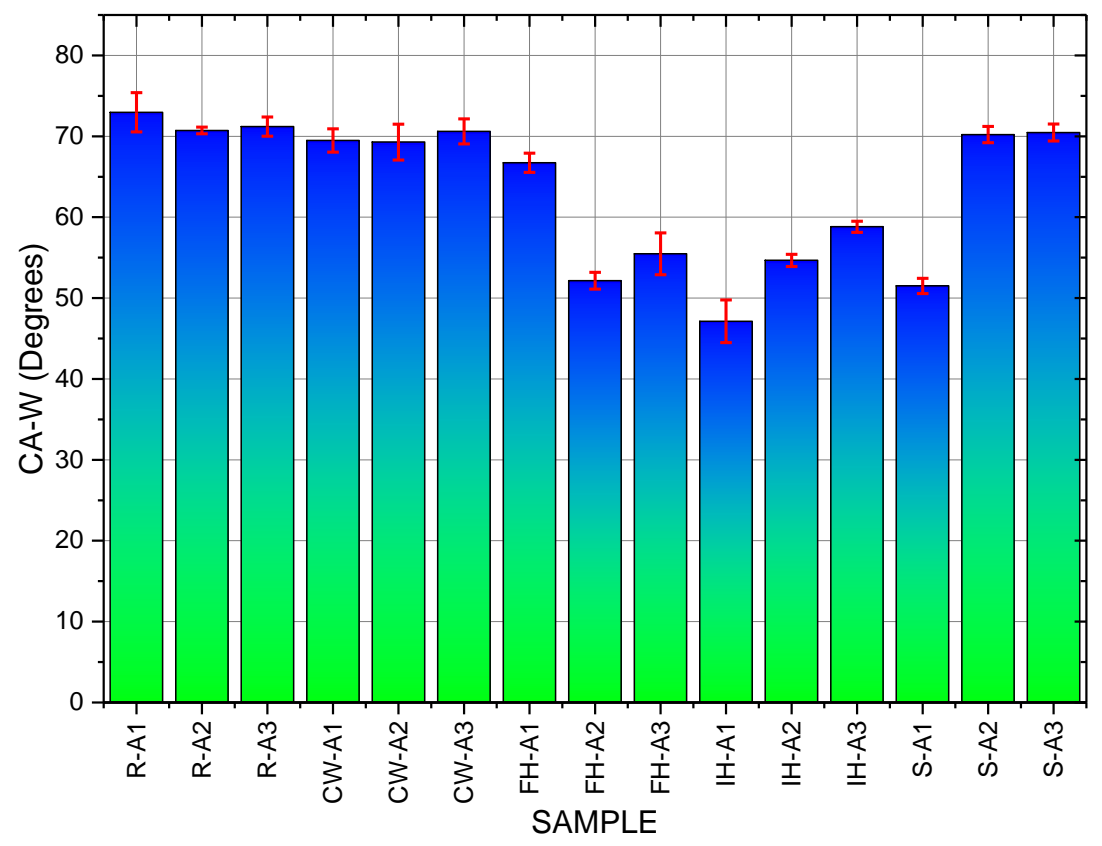

Figure 6. Contact angle variation

On the R samples little variation was observed on the contact angle value that averages $71.63^{\circ}$. The $\mathrm{CW}$ samples show similar contact angle values averaging $67.79^{\circ}$ with little variation. The heated sample FH and IH show a significant decrease in contact angle value, down to an average of $58.12^{\circ}$ for $\mathrm{FH}$ and $51.50^{\circ}$ for $\mathrm{IH}$. The variation between regions is significant given non-uniform heating and cooling of the surface $[9,10]$. Still, induction heating created a more uniform temperature distribution in the specimen since data spread is lower when compared to flame heating. For the $\mathrm{S}$ samples there is little spread between area A2 and A3 is insignificant, the average value of the contact angle is $70.34^{\circ}$, similar to the $\mathrm{R}$ sample, the original panel. Yet in area A1 the contact angle drops to $51.50^{\circ}$. In this region a spot weld was observed, as shown in Figure 7.

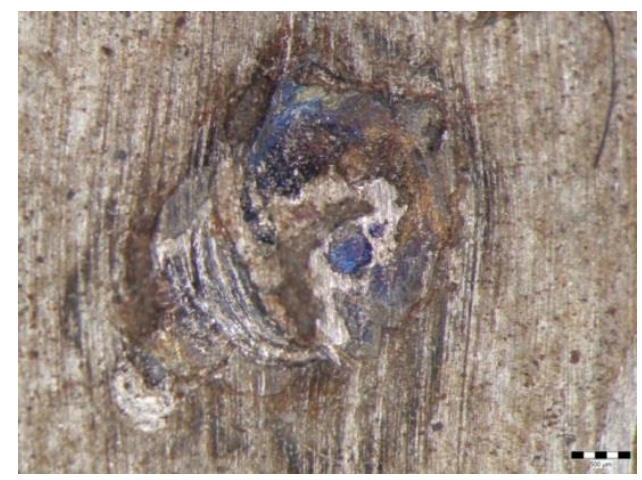

Figure 7. Spot weld appearance

When the spot welder is used heating is extremely localized and short, thus significant temperature increase does not occur as the distance increases from the heated region.

It can be seen that heating alters steel surface energy, making it more hydrophilic and thus more prone to corrosion. The surface free energy of the samples was determined using Fowkes's method [11]employing as liquids deionized water, diiodomethane and ethylene glycol. Tests were performed on regions previously established by performing three measurements for each liquid. 
The surface free energy was first computed using Eq. (1).

$$
\gamma_{s} \approx \gamma_{l}\left(\frac{(1+\cos (\theta))^{2}}{4 \Phi^{2}}\right)
$$

Here $\gamma$ stands for the surface free energy $(\mathrm{mN} / \mathrm{m})$ for the solid $\left(\gamma_{s}\right)$ and liquid $\left(\gamma_{l}\right)$, and $\Phi$ is the interfacial interaction parameter as described by Girifalco and Good [12] and $\theta$ the value of the measured contact angle (degrees). To determine the interfacial interaction parameter Eq. (2) can be used:

$$
\Phi=\frac{4 \sqrt[3]{V_{s} V_{l}}}{\left(\sqrt[3]{V_{s}}+\sqrt[3]{V_{l}}\right)^{2}}
$$

where $\mathrm{V}$ is the molar volume of the solid $\left(V_{s}\right)$ and liquid $\left(V_{l}\right)\left(\mathrm{cm}^{3} / \mathrm{mole}\right)$. The molar mass of steel used in the computation was approximated at $55.845 \mathrm{~g} / \mathrm{mole}$ [13] given the low content of alloying elements. The liquid used for computation was water. In Figure 8 a comparison of the computed surface free energies using Eq. (1) and Fowkes method is presented.

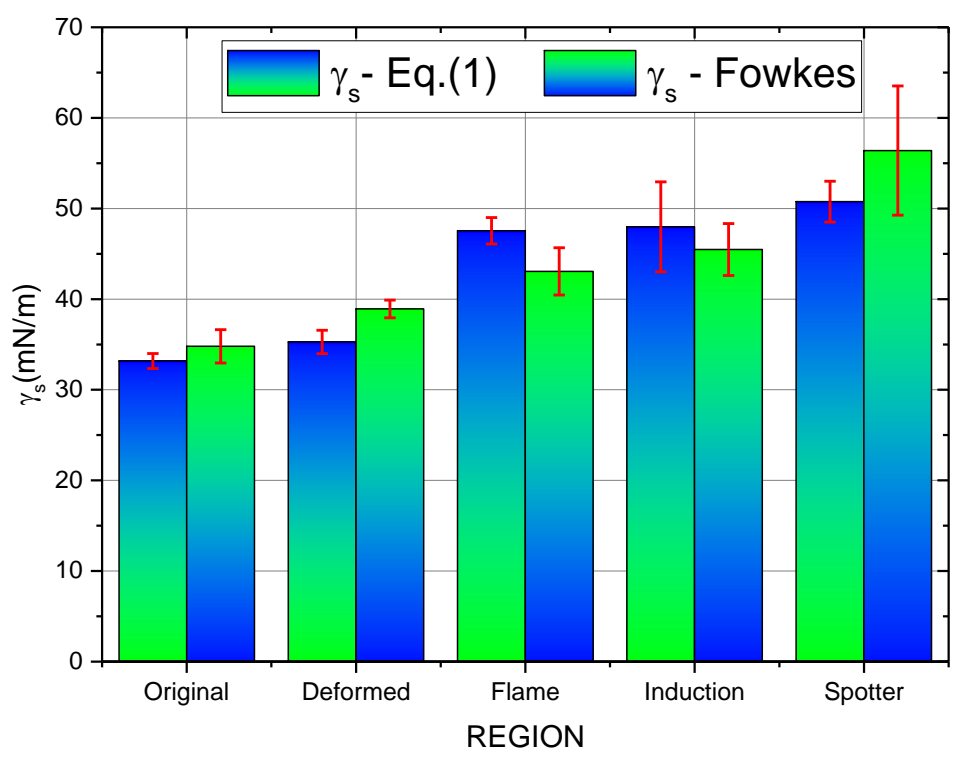

Figure 8. Comparison of the surface free energies

It can be seen that when using Eq.(1) an increase in the value of the surface free energy is predicted when sample heating is performed. On deformed surfaces a slight increase can be observed, while on the heated regions significant increase in surface free energy occurs. When the surface free energy was computed using Fowkes's method a similar occurrence was observed: heated specimens showed significant surface free energy increase. Metallic materials usually have high surface free energies which means a higher tendency to adsorb molecules to their surface, thus creating good premises for corrosion[14-17].

\subsection{Corrosion}

The corrosion tests were performed on samples prepared according to ASTM G5-94(2011) that were cut from damaged and straightened regions and one sample was obtained from an original car panel. 
The corrosion medium chosen for this test was a 3.5\% NaCl solution. The Tafel curves obtained for the samples are shown in Figure 9.

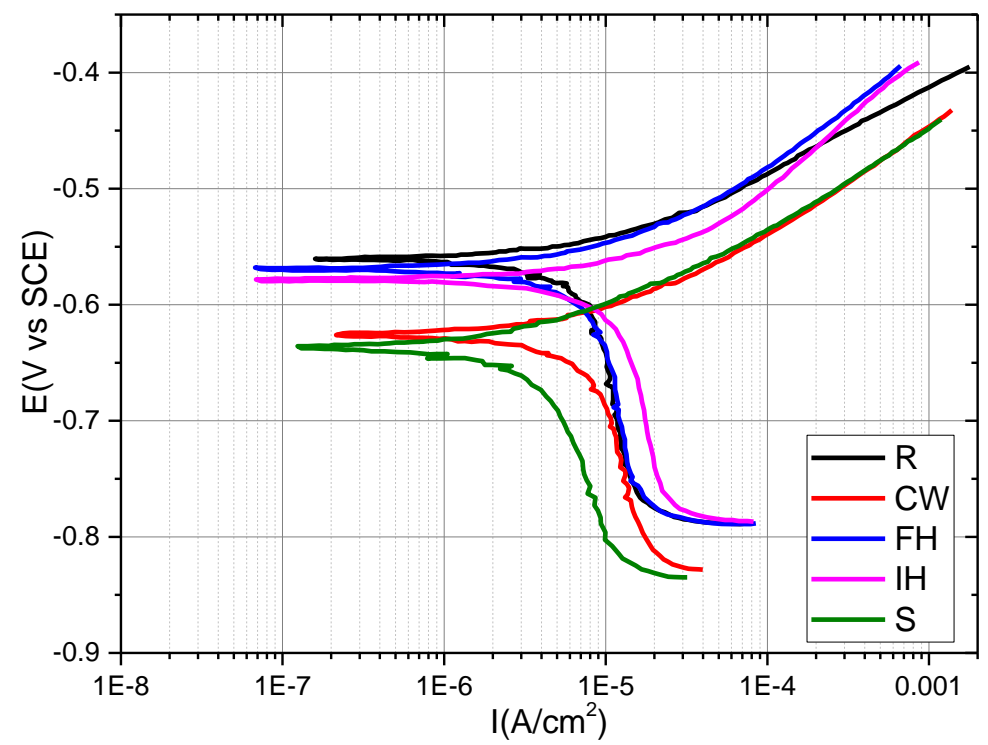

Figure 9. Tafel curves for the samples

Using the curves the open circuit potential $\mathrm{E}_{\mathrm{OC}}$ and the corrosion potential $\mathrm{E}_{\mathrm{COR}}$ were determined and compared, as shown in Figure 10.

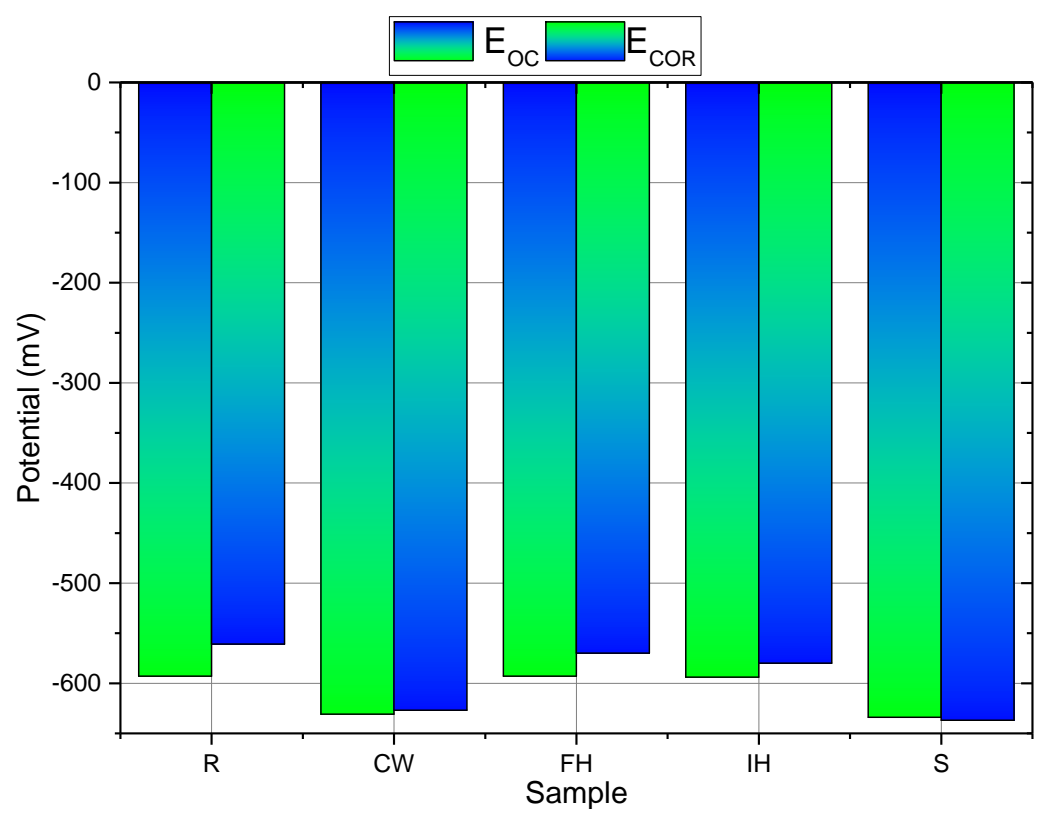

Figure 10. Comparison of open circuit and corrosion potential

From an open circuit potential point of view it can be stated that a more electropositive value suggests a good corrosion behavior $[18,19,20]$, thus samples R with $-593 \mathrm{mV}$, FH with $-593 \mathrm{mV}$ and IH with $594 \mathrm{mV}$ open circuit potential are more noble. When the corrosion potential is used as criteria [21, 22, 23], again, a more electropositive value reflects a better corrosion behavior and, in this case, sample R with $-561 \mathrm{mV}$ potential has the best corrosion behavior, followed by sample FH with $-570 \mathrm{mV}$ and $\mathrm{IH}$ with $-580 \mathrm{mV}$. Worst corrosion behavior was attributed to sample $\mathrm{S}$, its corrosion potential is $637 \mathrm{mV}$ a little lower than that if sample $\mathrm{CW}$ with $-627 \mathrm{mV}$. Another useful parameter that can be used 
for corrosion behavior assertion is the corrosion current density [24], but since it is obtained as function of sample surface it was considered irrelevant for this study. The samples are nonhomogeneous from microstructure and stress and strain state point of view. A study was performed using the Olympus SZX7 stereomicroscope on the surface of the corroded samples, aspects from this study are presented in Figure 11.

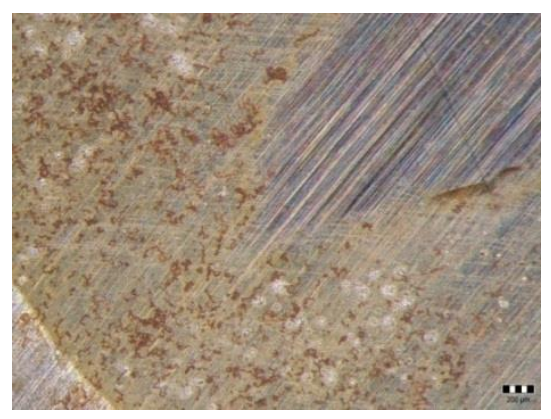

a.

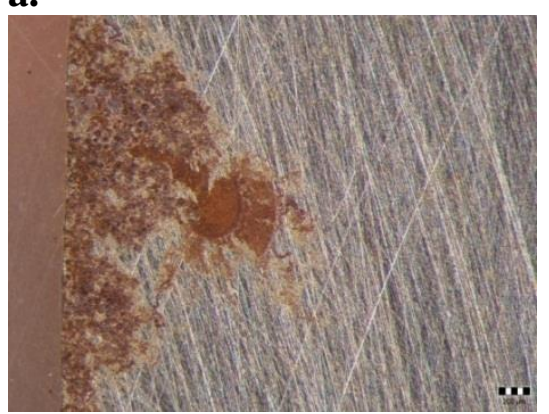

c.

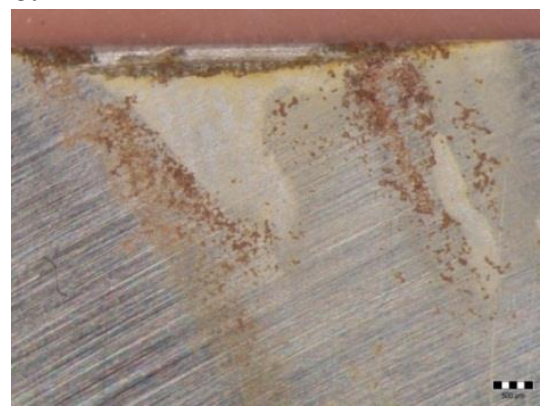

e.

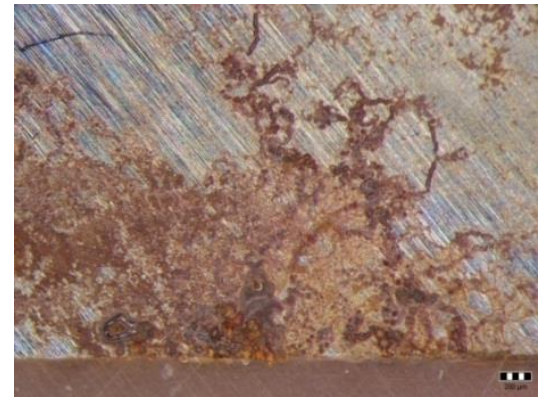

b.

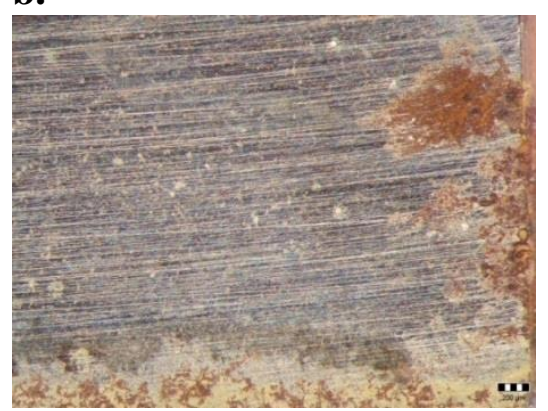

d.

Figure 11. Corrosion aspects on the surface of the sample a. R, b. CW, c. FH, d. IH and e. S

On the surface of $\mathrm{R}$ sample the distribution of corrosion features suggests that general corrosion occurred, where the entire surface was affected in a similar extent, detail shown in Figure 11.a. The CW sample shows preferred regions for corrosion, as presented in Figure 11.b, mostly located where the metal was straightened by hammering. On the surface of the specimens straightened by heating, sample FH and IH, shown in Figure 11.c and d, again a more localized attack occurs in the heated or heat affected region, and in the S sample, as shown by Figure 11. e, the regions are strongly affected by corrosion are where the weld spot was present and where the material was deformed when pulled.

\section{Conclusions}

Straightening of sheet metal from car panels is a common practice when the damaged area is small to medium. In the repair shops three common procedures are employed: hammering, heating or using a spot weld puller, sometimes these procedures are used in association. The aim of this study was to observe the change in the steel behavior in corrosion when its state is altered by straightening. Regarding surface wetting it was observed that when heating is used for straightening the contact angle value decreases, the surface becomes more hydrophilic, and prone to corrosion. The surface free 
energy of the steel appears to be higher than the reference when straightened by heating, yet the highest value was observed in the vicinity of the spot weld - higher surface free energy means a higher tendency for molecules to adsorb to the surface and enhance the corrosion. The corrosion tests revealed that when spot weld pullers were used for straightening, the worst corrosion behavior was observed, closely followed by the samples straightened by hammering. Straightening by heating did not alter the corrosion behavior in a significant manner. From this study it can be stated that car panels straightened by hammering and using a spot weld puller show the worst corrosion behavior. A compromise is required in order to ensure good mechanical properties and corrosion resistance, since these methods yielded best mechanical characteristics.

Acknowledgment: The work has been funded by the Operational Programme Human Capital of the Ministry of European Funds through the Financial Agreement 51668/09.07.2019, Project POCU MySMIS code 124705.

\section{References}

1. JAMES E. D., , Auto Body Repair Technology, fifth edition, Delmar Cengage Learning, ISBN10:1-4180-7353-9, USA, 2009, p. 323-350.

2. ADRIAN COSTIN D., RADU I., ION D., ALIN D., MARIUS V., Experimental Research on the Triangular Lattice Type Polymer Based Composites Structures for Sandwich Panels Construction, Mater Plast, 54(4), 2017, p. 639-644.

3. SORIN D., MIRCEA D., MARIUS V., Titanium and Titanium-Based Alloys for Aerospace, Metal Int, 14(7), 2009, p. 14-18.

4. MARIUS V., IOANA V., Contributions Regarding the Corrosion Behaviour of Some Al-Cu-Mg Superalloys, Rev Chim, 60(1), 2009, p. 23-28.

5. ALEXANDRA B., MARIA M., OCTAVIAN R., CRISTIAN P., MARIUS V., Electrodissolution studies of three aluminum alloys in acid, neutral and alkaline solutions, Rev Roum Chim, 51(3), 2006, p. 193-198.

6. NICOLAE N., MIHAI B., ROBERT C., ION C., RAZVAN C., ANCA DANIELA R., AUGUSTIN S., IULIAN A., SEBASTIAN G., IOAN C., Effect of Local Heating on the Mechanical Characteristics of Repaired Automotive Panels, Mater Plast, 56(4), 2019, p. 750-758.

7. ROBERT C., NICOLAE N., ALIN D., OCTAVIAN T., ClAUDIA M., ION C., RAZVAN C., VICENTIU S., Surface Repairs by Mmaw and Mig - Influences on Fracture Energy., Univ Politeh Buchar, 81(3), 2019, p. 209-218.

8. NICOLAE N., ROBERT C., OCTAVIAN T., IULIAN A., Materials for automotive industry and their influence on the dynamics of a car crash, JESR, 25(2), 2019, p. 25-32.

9. RAMESH G., PRABHU K. N., Wetting and Cooling Performance of Mineral Oils for Quench Heat Treatment of Steels, Isij Int, 54(6), 2014, p. 1426-1435.

10. MAEDEH P., JOSEPH R. MC D., Effect of Annealing Temperature on the Selective Oxidation and Reactive Wetting of a $0.1 \mathrm{C}-6 \mathrm{Mn}-2 \mathrm{Si}$ Advanced High Strength Steel During Continuous Galvanizing Heat Treatments, Isij Int, 58(9), 2018, p. 1635-1643.

11. ADELINE R., ALAE EL H., ODILE F., SOPHIE C., Surface free-energy determination of copper wire using a large range of model liquids, Sn Appl Sci, 2, 2020.

12. GIRIFALCO, L.A., GOOD, R.J., A theory for the estimation of surface and interfacial energies I. Derivation and application to interfacial tension, J. Phys. Chem., 61(7), 1957, p. 904-909.

13. AlEXANDRE, B.; CAPRANI, A.; CHARBONNIER, J. C.; KEDDAM, M.; MOREL, P.: The Influence of Chromium on the Mass-Transfer Limitation of the Anodic-Dissolution of Ferritic Steels Fe-Cr in Molar Sulfuric-Acid, Corros Sci, 21, 1981, p. 765-780.

14. SAJJAD A., MOHAMED R., BAHRAM R., Inspection the corrosion prevention performance and dry/wet interfacial adhesion qualities of the melamine-cured polyester coating applied on the treated 
mild steel surface with a nanostructured composite cerium-neodymium film, Colloid Surface A, 590, 2020, p. 1-13.

15. TOSHIYASU N., Electrochemical Behavior of Steel in Concrete Under Wet and Dry Condition with NaCl Solution, J Mater Eng Perform, 28(5), 2019, p. 1500-1508.

16. WEN, J.; LUNDIN, C. D.: Surface-Tension of 304 Stainless-Steel under Welding Conditions Influence of Shielding Gases Is Evaluated, Weld J, 65, 1986, p. S138-S138.

17. ALES K., LENKA R., SIMONA Z., MONIKA K., BEDRICH S., Calculation of Surface Tension of Real Steel Grades at 1550 Degrees C, Metal 2015: 24th International Conference on Metallurgy and Materials, 2015, p. 91-95.

18. IULIAN A., FLORIN M., COSMIN C., ANTON F., JULIETA V.R., ELENA G., AURORA A., CAMELIA T., IOAN C., Controlling the Degradation Rate of Biodegradable Mg-Zn-Mn Alloys for Orthopedic Applications by Electrophoretic Deposition of Hydroxyapatite Coating, Materials, 13(2), p. 263.

19. MARIANA C., IOANA-ARINA G., SORIN C., ALINA N., COSMIN C., RUXANDRA ELENA D., Heat Treatment Influence on the Corrosion Resistance of a Cu-Al-Fe-Mn Bronze, Rev Chim, 69(5), 2018, p. 1055-1059.

20. FLORIN M., IONUT J., GEROGE E. S., MARIAN M., STEFAN IOAN V., COSMIN C., TEODOR MACHEDON P., SORN C., Tailoring the electric and magnetic properties of submicronsized metallic multilayered systems by TVA atomic inter-diffusion engineered processes, Appl Surf Sci, 358, 2015, p. 619-626.

21. COSMIN MIHAI C., VIOREL B., MIHAI B., IRINA T., MAIANA B., ANCA P., Corrosion resistance, mechanical properties and biocompatibility of Hf-containing $\mathrm{ZrCN}$ coatings, Thin Solid Films, 538, 2013, p. 48-55.

22. CRISTIAN P., ANDREI CONSTANTIN B., GEORGE C., MIRELA 0., ANDRA MIHAELA P., ECATERINA M., RUXANDRA ELENA D., SORIN C., IOANA G., Corrosion Resistance Evaluation of Some Stainless Steels Used in Manufacture of Hydraulic Turbine Runner Blades, Rev Chim, 70(7), 2019, p. 2491-2496.

23. DORINEL T., ANCA C., RALUCA IOANA Z., MARIN B., SORIN C., Comparative Tests on Resistance to Corrosion of Some Nanocomposites Based on Titanium-Hydroxyapatite, Univ Politeh Buchar, 78(2), 2016, p 185-194.

24. ROBERT C., RAZVAN C., OCTAVIAN T., ANCA DANIELA R., MIHAI V., ION C., NICOLAE N., IOAN C., Corrosion Behavior of Welded Repaires for Water Turbine Blades, Rev Chim, 70(7), 2019, p. 2497-2501.

Manuscript received: 19.03 .2020 